\title{
Avian and swine influenza viruses: our current understanding of the zoonotic risk
}

\author{
Kristen VAN REETH* \\ Laboratory of Virology, Faculty of Veterinary Medicine, Ghent University, Belgium
}

(Received 11 July 2006; accepted 30 November 2006)

\begin{abstract}
The introduction of swine or avian influenza (AI) viruses in the human population can set the stage for a pandemic, and many fear that the Asian H5N1 AI virus will become the next pandemic virus. This article first compares the pathogenesis of avian, swine and human influenza viruses in their natural hosts. The major aim was to evaluate the zoonotic potential of swine and avian viruses, and the possible role of pigs in the transmission of AI viruses to humans. Cross-species transfers of swine and avian influenza to humans have been documented on several occasions, but all these viruses lacked the critical capacity to spread from human-to-human. The extreme virulence of $\mathrm{H} 5 \mathrm{~N} 1$ in humans has been associated with excessive virus replication in the lungs and a prolonged overproduction of cytokines by the host, but there remain many questions about the exact viral cell and tissue tropism. Though pigs are susceptible to several AI subtypes, including $\mathrm{H} 5 \mathrm{~N} 1$, there is clearly a serious barrier to infection of pigs with such viruses. AI viruses frequently undergo reassortment in pigs, but there is no proof for a role of pigs in the generation of the 1957 or 1968 pandemic reassortants, or in the transmission of H5N1 or other wholly avian viruses to humans. The major conclusion is that cross-species transmission of influenza viruses per se is insufficient to start a human influenza pandemic and that animal influenza viruses must undergo dramatic but largely unknown genetic changes to become established in the human population.
\end{abstract}

influenza / birds / pigs / pathogenesis / zoonosis

\section{Table of contents}

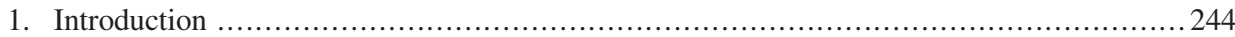

2. Characteristics of avian, swine and human influenza viruses .............................. 245

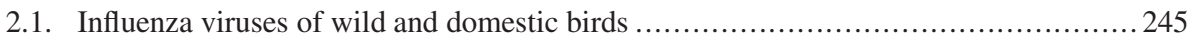

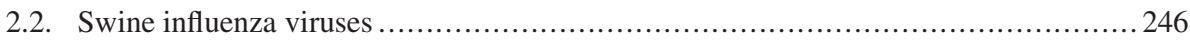

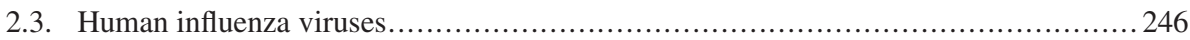

3. The pathogenesis of influenza viruses in their native hosts ................................ 248

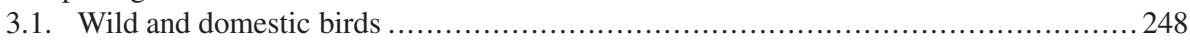

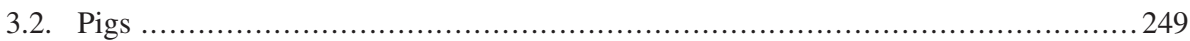

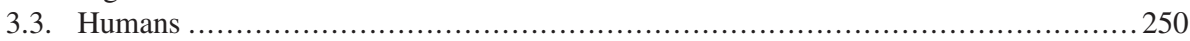

4. The zoonotic potential of swine and avian influenza viruses ...............................250

4.1. Human infections with swine influenza ........................................... 250

4.2. Human infections with avian influenza ........................................... 252

*Corresponding author: kristien.vanreeth@Ugent.be 
4.3. Swine as an intermediate host for the transmission of avian influenza viruses to

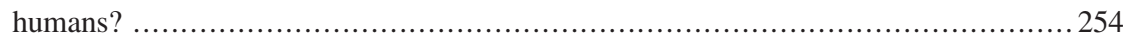

5. General considerations on the species barrier and conclusions ............................. 256

\section{INTRODUCTION}

Influenza A viruses are enveloped, single stranded RNA viruses in the family Orthomyxoviridae (reviewed in [57]). Two other types of influenza - type B and C also occur in humans, but they are unimportant for animals and are beyond the scope of this paper. Influenza A viruses are further classified into subtypes based on the antigenic properties of the external glycoproteins haemagglutinin (HA) and neuraminidase (NA). The $\mathrm{HA}$ and $\mathrm{NA}$ are very important for the induction of an antibody response in the host, but they are also highly variable while the "internal" proteins like the nucleoprotein (NP) and matrix $(\mathrm{M})$ proteins are more conserved between different influenza A viruses. Sixteen antigenically different HA (H1-H16) and 9 different NA (N1-N9) have been recognised so far, and their combination designates the subtype of the virus. Influenza viruses are genetically unstable, and the reader is referred to [57] for a detailed overview of the mechanisms of antigenic drift and shift.

There are large pools of influenza viruses covering all known subtypes in wild birds, especially ducks and geese, which function as the reservoir for influenza viruses in domestic birds and mammals (reviewed in $[39,50]$ ), notably humans, pigs, horses, seals, ferrets and mink. Influenza virus transmission between species is rare, but it may have serious consequences if it occurs. The introduction of an avian or swine influenza virus in the human population, for example, may set the stage for an influenza pandemic, provided that humans have no immunity to the virus and that it spreads efficiently from person to person. In 1976, the Americans started a national emergency vaccination campaign to prevent a dreaded human pandemic due to a swinelike H1N1 influenza virus. But the vaccination campaign was rapidly halted because of safety issues and it turned out to be unnecessary. Until some 10 years ago, human infections with avian influenza (AI) viruses were considered rare events and it was thought that AI virus transmission to humans must occur via the pig as an intermediate host. But during the last decade, there has been a significant increase in the number of AI infections in humans. A "highly pathogenic" AI virus, subtype H5N1, has not only crossed the species barrier to humans but is also highly lethal for humans. Many fear that H5N1 may become the next human pandemic influenza virus and the governments of most European countries have spent millions of Euros on "pandemic preparedness" plans. According to others, the scale of the warnings appears to outstrip the magnitude of the threat, and the author of this article shares this opinion. Indeed, cross-species transmission of animal viruses in itself is usually not sufficient for spread into the human population and generation of a pandemic. One very positive effect of $\mathrm{H} 5 \mathrm{~N} 1$ is that it has boosted research on the adaptive processes of influenza viruses in new hosts and on influenza pathogenesis in non-native hosts. In addition, $\mathrm{H} 5 \mathrm{~N} 1$ and other $\mathrm{AI}$ viruses have also changed our understanding of the potential role of pigs as intermediate hosts.

This review is aimed at presenting a critical analysis of the zoonotic potential of swine and avian influenza viruses, with emphasis on viral pathogenesis and on $\mathrm{H} 5 \mathrm{~N} 1$, and of the possible role of pigs in $\mathrm{AI}$ 
virus transmission to humans. I start with a brief comparison of the characteristics of avian, swine and human influenza viruses and of the viral pathogenesis in the natural host. Some terms that are used throughout the paper are defined here to avoid confusion. A host is considered "susceptible" to infection with a given influenza virus if the virus enters and replicates to a smaller or greater extent leading to seroconversion. This does not necessarily imply virus spread to other subjects. "Transmission" is the process by which the virus is shed from one animal and infects the next, causing a serological response. Further intraspecies transmission may or may not occur. "Adaptation" or "establishment" are considered to mean that the virus has become adapted to a certain host species so that it is fit for replication in that host and sustained intraspecies transmission.

\section{CHARACTERISTICS OF AVIAN, SWINE AND HUMAN INFLUENZA VIRUSES}

\subsection{Influenza viruses of wild and domestic birds}

Wild birds frequently become infected with influenza viruses and feral water birds including ducks, geese, terns, shearwaters and gulls are most susceptible (reviewed in $[1,39,50])$. While influenza viruses that have become established in mammals show a restricted combination of HA and NA subtypes, 82 different combinations have been isolated from wild birds. The influenza virus replicates in the respiratory but primarly in the intestinal epithelia of ducks [56] and high amounts of virus are shed in the faeces (up to $10^{8.7} 50 \%$ egg infectious doses (EID50)/g duck faeces) for 3 to 4 weeks. Influenza virus has been isolated from untreated lake water where large numbers of waterfowl are found and it is efficiently transmitted between birds through the faecal-oral route via surface waters. Surveillance studies in wild birds in North America and Europe have revealed a high prevalence of viruses of low virulence for poultry. Isolation rates may reach up to $15 \%$ in ducks and up to $2.8 \%$ in other wild birds, but they also depend on the bird species and age, time and place. Several wild bird species have the potential to distribute influenza viruses between countries or even continents, because they are generally asymptomatic virus carriers.

Domestic poultry such as chickens and turkeys, commercially reared ducks and geese, quails, pheasants, ratites and caged pet birds are also susceptible to influenza. Influenza viruses infecting domestic poultry can be divided into two distinct groups based on their clinical manifestations in chickens. The highly pathogenic avian influenza (HPAI) viruses have been restricted to subtypes $\mathrm{H} 5$ and $\mathrm{H} 7$, though not all viruses of these subtypes are HP, and cause severe disease with mortality up to $100 \%$. All other viruses are low pathogenic (LP) and cause a much milder, primarily respiratory disease. The HA plays a central role in the pathogenicity of AI viruses, as further explained in the section on pathogenesis. The cases of both HPAI and LPAI in domestic poultry appear to result from the introduction of influenza virus from wild birds. Once introduced in the poultry population, influenza viruses can spread between poultry farms by a number of methods and particularly by mechanical transfer of infective faeces. Importantly, LP H5 and H7 AI viruses that have been introduced into poultry flocks from wild birds may mutate into HP viruses after a short or long time of circulation in the poultry population. Only 24 outbreaks of HPAI have been recorded worldwide since 1959 and most of these outbreaks showed limited geographical spread.

The Asian HP H5N1 virus, however, is somewhat exceptional $[31,48]$. This virus has been circulating in Asia since 1996 and 
it led to the culling of millions of poultry in Hong Kong in 1997. Despite the eradication of H5N1 from Hong Kong, its precursors continued to circulate in ducks and geese in south China in which they caused largely subclinical infections. In the winter of 2003-2004 very severe outbreaks of H5N1 were almost simultaneously reported in 8 countries in South-East Asia - South Korea, Vietnam, Japan, Cambodia, Indonesia, Thailand, China and Laos and the virus is now enzootic in several of them. The virus has subsequently spilled over from poultry into the wild bird population and, unexpectedly, has killed thousands of migratory birds at the Qinghai Lake nature reserve in China [39]. Since 2005-2006 H5N1 infections in wild birds and/or poultry have also been reported in Russia, Turkey and several Eastern European countries, and some countries in Western Europe and Africa. The H5N1 cases in wild birds in European countries without outbreaks among poultry suggest that wild birds may have spread H5N1 to unaffected regions, though this issue remains much debated.

\subsection{Swine influenza viruses}

Influenza viruses of three different subtypes - H1N1, H3N2 and H1N2 - are circulating in swine worldwide (reviewed in [38]). Unlike for human influenza viruses, the origin and nature of swine influenza viruses (SIV) differ on different continents. The predominant H1N1 SIV in Europe, for example, are entirely of avian origin and they were introduced from wild ducks into the pig population in 1979. Two types of H1N1 SIV, in contrast, are circulating in the USA: the so-called "classical" $\mathrm{H} 1 \mathrm{~N} 1$ viruses that have been present since the early 20th century and novel reassortants with the surface glycoproteins of the classical virus and internal proteins of more recently emerged $\mathrm{H} 3 \mathrm{~N} 2$ or
H1N2 SIV. Viruses of both other subtypes, $\mathrm{H} 1 \mathrm{~N} 1$ and $\mathrm{H} 3 \mathrm{~N} 2$, also have a different origin in Europe and in the USA and were introduced in the swine population at different times (Tab. I). These differences between SIV in different parts of the word also have implications for the diagnosis and control of SIV, and the strains used as antigens in vaccines and diagnostic tests also differ in Europe and in the USA. It is remarkable that most SIV are reassortants with mixtures of human, avian and swine virus genes. This supports the classical notion that pigs are susceptible to both human and avian influenza viruses, and that they can serve as "mixing vessels" for those viruses. Antigenic drift within SIV lineages does occur but it is less prominent than antigenic drift with human influenza viruses. The current European H1N1 and H3N2 SIV, for example, still show some degree of cross-reactivity with SIV from the 1980 s, while replacement of human influenza virus variants occurs more quickly. SIV are readily transmitted by contact with respiratory secretions from infected pigs as well as by the air. It is therefore impossible to prevent SIV infections by sanitary measures alone, and the virus is enzootic in most densely swine populated regions. In serological investigations in Flanders, Belgium, in 2001 and 2003, most individual sows had antibodies to a combination of two $(48 \%)$ or to all three $(31 \%)$ subtypes, indicating consecutive or simultaneous infections with several SIV subtypes during their lifetime. Similar findings have been made in Germany, Italy and Spain, where all three subtypes are also widespread.

\subsection{Human influenza viruses}

Influenza virus subtypes that have become established in humans have been limited to H1, H2, H3, N1 and N2 (reviewed in $[12,18,57])$. Currently circulating strains are $\mathrm{H} 1 \mathrm{~N} 1, \mathrm{H} 3 \mathrm{~N} 2$ and $\mathrm{H} 1 \mathrm{~N} 2$, but 
Table I. Influenza A virus subtypes infecting pigs endemically in Europe and North America and their antigenic/genetic characteristics.

\begin{tabular}{|c|c|c|c|}
\hline Continent & Subtype & Year of introduction & Antigenic/genetic characteristics \\
\hline \multirow[t]{7}{*}{ Europe } & H1N1 & 1979 & Wholly avian virus \\
\hline & $\mathrm{H} 3 \mathrm{~N} 2$ & $1984^{\mathrm{a}}$ & Reassortant \\
\hline & & & human H3N2 (Hong Kong /68-like HA and NA) \\
\hline & & & $X$ swine H1N1 \\
\hline & $\mathrm{H} 1 \mathrm{~N} 2$ & 1994 & Reassortant \\
\hline & & & human H1N1 (England/80-like HA) \\
\hline & & & $X$ swine H3N2 (NA) X swine H1N1 \\
\hline \multirow[t]{9}{*}{ North America } & H1N1 & 1918 & "Classical" SIV \\
\hline & H1N1 & 1998 & Reassortant \\
\hline & & & $\begin{array}{l}\text { classical SIV }(H A, N A) X \text { triple reassortant } \\
\text { swine H3N2 OR swine H1N2 }\end{array}$ \\
\hline & $\mathrm{H} 3 \mathrm{~N} 2$ & 1998 & Reassortant \\
\hline & & & human H3N2 (HA, NA) X classical SIV \\
\hline & $\mathrm{H} 3 \mathrm{~N} 2$ & 1998 & "Triple" reassortant \\
\hline & & & human H3N2 (HA, NA) X classical SIV X avian \\
\hline & H1N2 & 1998 & Reassortant \\
\hline & & & classical SIV (HA) X triple reassortant H3N2 (NA) \\
\hline
\end{tabular}

Progenitor virus lineages of the reassortant SIV are shown in Italics.

${ }^{a}$ A wholly human Hong Kong/68-like influenza virus was already transmitted to pigs in the early 1970s, but genetic reassortment with the "avian-like" H1N1 SIV occurred in the mid 1980s.

these viruses are antigenically and genetically different from their counterparts in swine. The H3N2 virus was introduced in 1968, when it caused the so-called "Hong Kong" pandemic and replaced the preceding $\mathrm{H} 2 \mathrm{~N} 2$ virus. The new pandemic virus was a reassortant between an avian influenza virus, providing the $\mathrm{H} 3 \mathrm{HA}$ and polymerase B1 genes, and the circulating human $\mathrm{H} 2 \mathrm{~N} 2$ strain, which was the donor of the N2 NA and five other genes. H1N1 circulated among humans from the early 20th century until 1950, when it temporarily disappeared, and was reintroduced in 1977. There are few seroprevalence data for human influenza viruses, but significant influenza epidemics occur about every 3 years during the winter season. Both $\mathrm{H} 1 \mathrm{~N} 1$ and $\mathrm{H} 3 \mathrm{~N} 2$ have been asso- ciated with these epidemics, but H3N2 viruses show more rapid antigenic drift than the H1N1 subtype and they are most frequently involved in epidemics. Starting in 2001, influenza viruses of the H1N2 subtype have also been isolated from humans [12]. These viruses are reassortants between the circulating $\mathrm{H} 1 \mathrm{~N} 1$ and $\mathrm{H} 3 \mathrm{~N} 2$ viruses, but their prevalence and clinical importance are unclear. Novel influenza virus strains or variants that arise in one continent generally spread rapidly to other continents, where they cause outbreaks during the colder months of the year. Transmission of influenza between humans occurs via the respiratory route, mainly by direct person-to-person spread. Preschool and school age children, who are largely immunologically naive, play a major role 
in the transmission of influenza viruses in the community.

\section{THE PATHOGENESIS OF INFLUENZA VIRUSES IN THEIR NATIVE HOSTS}

\subsection{Wild and domestic birds}

The course and clinical outcome of an influenza infection is dramatically different in wild versus domestic birds (reviewed in $[1,50])$. In wild birds, the infection is almost invariably asymptomatic. Most influenza viruses isolated from free-living birds, including those of $\mathrm{H} 5$ and $\mathrm{H} 7$ subtypes, are also low pathogenic (LP) for poultry. Isolations of HPAI viruses from feral birds are rare and occur mainly in the vicinity of HPAI outbreaks in poultry. This is in line with the hypothesis that HP H5 or $\mathrm{H} 7$ viruses emerge after the introduction of a LPAI virus from wild ducks to poultry, in which such viruses can mutate to their pathogenic phenotype. Interestingly, viruses that are HP for poultry usually replicate poorly or to a limited degree in wild birds and they are seldom pathogenic. Notable exceptions have been the 1961 H5N3 HPAI outbreak in common terns in South Africa, and of course the currently circulating HP H5N1 virus. The H5N1 virus has caused disease and death among migratory geese populations in western China. The increased virulence of some of the recent $\mathrm{H} 5 \mathrm{~N} 1$ isolates for some duck species has also been confirmed in experimental studies [49]. Nevertheless, some recent $\mathrm{H} 5 \mathrm{~N} 1$ isolates still cause minimal disease in ducks and several bird species may be asymptomatic carriers of H5N1.

In domestic birds, the clinical manifestations of influenza are largely dependent on the pathotype of the virus. Most strains of influenza virus are LP and will cause an asymptomatic or mild infection. However, a few strains produce a systemic infection with invasion of the central nervous system and high mortality. These HPAI viruses are invariably members of the $\mathrm{H} 5$ or $\mathrm{H} 7$ subtypes, but not all $\mathrm{H} 5$ or $\mathrm{H} 7$ strains are highly pathogenic. LP and HPAI viruses show structural differences at the so-called cleavage site of the precursor of the viral HA, which must be cleaved into HA1 and HA2 for the virus to become infectious. The LPAI viruses have only one or a few basic amino acids at this site and cleavage occurs exclusively by trypsin-like host proteases. Virus replication is therefore restricted to sites in the host where such enzymes are found, i.e. the epithelia of the respiratory and intestinal tracts. HPAI viruses, in contrast, possess multiple basic amino acids at their HA cleavage site and can be cleaved by a broad range of cellular proteases. Consequently, the tissue tropism of HPAI viruses is not restricted to the respiratory and intestinal tract. These viruses invade the submucosa and enter vascular or lymphatic systems to replicate and cause lesions in a variety of cell types in visceral organs, brain and skin. Mortality may reach $100 \%$ within one week and possible symptoms are cessation of egg laying, respiratory signs, sinusitis, oedema of the head and face, subcutaneous haemorrhages with cyanosis of the skin, particularly of the head and wattles, diarrhoea and neurological signs.

However, clinical signs in poultry are also determined by other factors like age, environment, concurrent infections and the bird species in particular. Turkeys are considered among the most susceptible birds and they may experience serious respiratory disease problems after infection with LPAI viruses. Turkeys and domestic chickens are also most susceptible to HPAI viruses, which cause a fulminating disease or death before clinical signs can be observed. In domestic ducks and geese, however, even HPAI viruses often produce few clinical signs. 


\subsection{Pigs}

SIV is one of the rare primary respiratory pathogens of swine (reviewed in [38]). This means that the virus can induce disease and lung lesions on its own. Typical swine "flu" outbreaks are characterised by a rapid onset of high fever, dullness, loss of appetite, laboured abdominal breathing and coughing. Weight loss can be considerable, but mortality is low and recovery occurs within 7-10 days. All three virus subtypes (H1N1, H3N2, H1N2) have been associated with disease and there are no indications for differences in virulence between subtypes or strains. Paradoxically, however, subclinical infections are also very common and many if not most pigs become infected with one or more influenza virus subtypes without ever showing clinical signs. Furthermore, there is no doubt that SIV can also contribute to more chronic, multifactorial respiratory disease problems in combination with other viruses or bacteria.

SIV is the typical example of an acute respiratory tract infection. The virus replicates in epithelial cells of the entire respiratory tract, notably the nasal mucosa, tonsils, trachea and lungs, but almost never enters other tissues. There is a massive infection of epithelial cells of the bronchi, bronchioli and alveoli, and virus titres in the lungs may reach up to $10^{8}$ EID50 per gram lung tissue. Epithelial cell necrosis and an influx of neutrophils into the lung accompany the typical respiratory disease. These inflammatory cells cause obstruction of the airways and substantial lung damage by release of their enzymes. Both the infection and disease are very transient, and virus excretion in nasal swabs and virus replication in the lungs last for 6-7 days at the most. Virus has occasionally been isolated from the serum of experimentally infected pigs, in barely detectable amounts, but virus isolation from extra-respiratory tissues is very rare. In one intranasal infection study, 1 of 4 influenza viruses examined was isolated from the faeces of a single pig, but virus replication in intestinal cells has never been demonstrated [25].

One intriguing question is why the typical SIV symptoms result in some but not in most cases of SIV infection. We have indications from experimental infection studies that the virus load in the lungs and the resulting release of inflammatory mediators by the host are crucial determinants for disease development. Under experimental conditions, the typical disease and lung pathology only result when pigs are inoculated with high virus doses directly into the trachea. In such intratracheal infection studies, we found massive virus titres in the lungs and high levels of several cytokines, or "signal molecules", in lung lavage fluids [53]. The cytokines included interferon-alpha (IFN- $\alpha$ ), tumour necrosis factor-alpha (TNF- $\alpha$ ), interleukin-1 (IL-1) and IL-6. These cytokines are known to cause lung inflammation, functional lung disturbances, fever, malaise and loss of appetite, and they can strongly enhance each other's effects. These symptoms were seen within $24 \mathrm{~h}$ after intratracheal inoculation of pigs with SIV and they were associated with the peak of virus replication and peak cytokine levels. In contrast, inoculation by the less invasive intranasal or aerosol inoculation routes resulted in lower virus titres in the lungs. These infections remained clinically mild or subclinical and failed to induce the massive production of cytokines in the lungs. Similarly, cytokine production was strongly reduced or absent after SIV challenge of pigs that had been previously vaccinated against swine influenza, and this was associated with the reduction and/or prevention of virus replication and disease [54]. All these findings support the idea that a massive SIV replication in the lungs is required for the induction of cytokines, which in turn stimulate disease. Consequently, any factors (partial active 
or passive immunity, sanitary measures...) that will reduce the extent of virus replication are likely to prevent disease.

\subsection{Humans}

As in swine, influenza infections in humans range in severity from asymptomatic infections to serious illness with both upper and lower respiratory tract symptoms. Typical symptoms are fever, chills, headache, sore throat, myalgias, malaise and anorexia (reviewed in $[57,58]$ ). The infection is rarely fatal in young people, but mortality can occur in people older than 65 years and in those with underlying medical conditions. Influenza viruses of $\mathrm{H} 1 \mathrm{~N} 1$, H3N2 and H1N2 subtypes generally cause similar clinical manifestations.

The virus can be detected in both nasal and throat swabs and replicates in epithelial cells throughout the respiratory tract. Although no direct comparative data for man are available, several arguments point towards a greater susceptibility of the lower than the upper respiratory tract (reviewed in $[3,16,57])$. Experimental studies in human volunteers have shown that the amount of virus required to infect the lower respiratory tract is very small $(<5$ infectious units) and that about 100 -fold more virus is required to infect the nasopharynx. In addition, studies of naturally occurring cases have indicated the early occurrence of infection of the lower respiratory tract through detection of virus and abnormal pulmonary function tests. The most significant pathology is also present in the lower respiratory tract: destruction and denudation of large areas of epithelial cells may be seen in the trachea and bronchi, as well as in smaller peripheral airways and alveoli. Influenza is a significant cause of pneumonia in naive individuals, i.e. infants and young children undergoing first infection and all age groups after the introduction of new pandemic viruses such as in
1918, 1957 and 1968. The predominance of mild upper respiratory signs and general signs during seasonal influenza infections in adults, however, may be explained by partial preexisting immunity from previous infections. In studies of human volunteers experimentally infected with influenza A viruses, IL- 6 and IFN- $\alpha$ levels in respiratory secretions and IL-6 levels in the circulation appeared to be correlated with symptom severity and virus replication [20]. The pathogenesis of influenza is thus similar in swine and humans, and the same cytokines have been associated with the typical flu symptoms in both species.

Despite the systemic symptoms, efforts to detect viraemia or virus replication outside the respiratory tract have been largely unsuccessful. Only a few rare, and mainly fatal, cases revealed low quantities of infectious virus in the blood, internal organs, brain and cerebrospinal fluid (reviewed in [57]). While infection of the gastrointestinal tract is a constant finding in many bird species, it has never been virologically confirmed in infections with human influenza viruses. Interestingly, human influenza viruses were found to replicate in the respiratory tract of ducks, but not in the intestinal tract [56].

\section{THE ZOONOTIC POTENTIAL OF SWINE AND AVIAN INFLUENZA VIRUSES}

\subsection{Human infections with swine influenza}

SIV have been occasionally isolated from the respiratory secretions or lungs of humans in Europe, Asia and the USA. A complete overview of all documented human cases of SI is given in Table II. Most SIV infections in people are not clinically distinguishable from human influenza virus infections, but fatal cases have been seen in humans infected with 
Table II. Swine influenza viruses isolated from humans worldwide.

\begin{tabular}{|c|c|c|c|c|c|}
\hline Continent & Year & Country or state & Virus & Patient & Outcome \\
\hline \multirow[t]{4}{*}{ Europe } & 1986 & $\begin{array}{c}\text { The Netherlands } \\
\text { ( } 1 \text { case), } \\
\text { Switzerland ( } 2 \text { cases) }\end{array}$ & ${\mathrm{H} 1 \mathrm{~N} 1^{\mathrm{a}}}$ & $\begin{array}{l}3 \text { young men of whom } 2 \\
\text { in close contact with pigs }\end{array}$ & $\begin{array}{l}\text { Mild respiratory disease } \\
\text { ( } 2 \text { patients) or severe } \\
\text { pneumonia ( } 1 \text { patient) }\end{array}$ \\
\hline & 1993 & The Netherlands & H1N1 & Girl living on farm (5 years) & Severe pneumonia \\
\hline & 1993 & The Netherlands & $\mathrm{H} 3 \mathrm{~N} 2$ & 2 children ( 1 and 2 years) & Mild respiratory disease \\
\hline & 2002 & Switzerland & $\mathrm{H} 1 \mathrm{~N} 1$ & Swine farmer (50 years) & Influenza symptoms \\
\hline \multirow{11}{*}{$\begin{array}{l}\text { Asia } \\
\text { North } \\
\text { America }\end{array}$} & 2002 & Hong Kong & $\mathrm{H} 3 \mathrm{~N} 2$ & Child (10 months) & Mild respiratory disease \\
\hline & 1975 & & H1N1 & Boy (13 years) with & Fatal pneumonia \\
\hline & & & & Hodgkin's disease & \\
\hline & 1976 & New Jersey & H1N1 & $\begin{array}{c}\text { Approx. } \\
500 \text { people infected }\end{array}$ & 1 fatal case \\
\hline & 1979 & Texas & H1N1 & $\begin{array}{c}\text { Student (20 years) } \\
\text { after working at } \\
\text { a swine livestock show }\end{array}$ & Influenza symptoms \\
\hline & 1980 & Texas & $\mathrm{H} 1 \mathrm{~N} 1$ & $\begin{array}{l}\text { Boy (6 years) after visiting } \\
\text { a regional livestock show }\end{array}$ & Influenza symptoms \\
\hline & 1982 & Nevada & H1N1 & $\begin{array}{c}\text { Girl (5 years) } \\
\text { with leukaemia }\end{array}$ & Fatal pneumonia \\
\hline & 1988 & Wisconsin & H1N1 & $\begin{array}{l}\text { Woman (32 years, } \\
\text { 3rd trimester } \\
\text { of pregnancy) after } \\
\text { visiting a pig fair }\end{array}$ & Fatal pneumonia \\
\hline & 1991 & Maryland & H1N1 & $\begin{array}{l}\text { Laboratory animal caretaker } \\
\text { (27 years) in contact } \\
\text { with sick pigs }\end{array}$ & Fatal pneumonia \\
\hline & 1995 & Minnesota & H1N1 & $\begin{array}{c}\text { Woman ( } 37 \text { years) working } \\
\text { in a swine farm }\end{array}$ & Fatal pneumonia \\
\hline & 1997 & Wisconsin & H1N1 & $\begin{array}{l}2 \text { animal caretakers } \\
\text { (31 and } 39 \text { years) exposed to } \\
\text { experimentally infected pigs }\end{array}$ & Influenza symptoms \\
\hline
\end{tabular}

${ }^{a}$ All H1N1 viruses isolated from humans in Europe were avian-like; H1N1 viruses isolated from humans in the USA were "classical".

classical H1N1 SIV. During the so-called "New Jersey" incident in the USA in 1976, an approximate 500 humans became infected with an $\mathrm{H} 1 \mathrm{~N} 1$ virus identical to viruses isolated from pigs at that time, and a national emergency immunisation campaign was started. However, it has never been really proven that pigs were the source of the virus. The vaccination was halted after two months, because hundreds of vaccinates developed a neurological disease known as Guillain-Barré syndrome. In addition, the vaccination turned out to be unnecessary since the virus strain caused little or no disease in humans and in any case was not pandemic.

Antibodies to SIV may be present in up to $23 \%$ of humans with occupational exposure to pigs. In a study in humans in Wisconsin in 1996-1997, seropositivity 
to H1N1 SIV was significantly associated with being a farm owner or a farm family member, living on a farm or entering the swine barn $\geq 4$ days/week [37]. A more recent study also suggested seropositivity to H1N2 SIV among swine farmers and veterinarians in Iowa [34]. However, the presence of antibodies to swine H1N1 in humans was also tightly associated with a number of other factors, such as being $\geq 50$ years of age, having received the swine flu vaccine in 1976-1977 or having ever received any influenza vaccine. It is thus possible that SIV antibody titres in humans do not really correlate with infection with SIV and serological investigations must be interpreted with care. In every way, the total number of SIV isolations from humans is negligible compared to the number of people involved directly or indirectly in swine farming. Also, all confirmed cases had been in close contact with pigs and the SIV appear to lack the critical property to spread further from human to human.

\subsection{Human infections with avian influenza}

From 1959 to 1996 there had been only three reported human cases of AI and humans were considered to be at low risk of infection with AI viruses. During the last decade, human infection with an AI virus has been reported on seven occasions (Tab. III) and all cases were due to direct contact with infected poultry. Only four AI virus subtypes - H5N1, H7N3, H7N7 and H9N2 - have been found in humans and most strains were HP $[4,28,30,42,47]$. The majority of AI viruses have spread to only one or a few people, but the HP H7N7 and $\mathrm{H} 5 \mathrm{~N} 1$ viruses have infected tens of humans and the latter virus is exceptionally virulent for humans.

The HP H7N7 outbreak in poultry in The Netherlands started in February 2003 and spread subsequently to eight farms in Belgium and 1 farm in Germany. Almost 31 million poultry in The Netherlands were culled before the virus was contained in May 2003. At least 89 people, 86 of whom had close contact with infected poultry, contracted the H7N7 virus. Most of these people had conjunctivitis but no influenza-like symptoms and the virus loads in throat/nose swabs were much lower than in conjunctival swabs, suggesting that the $\mathrm{H} 7 \mathrm{~N} 7$ virus had a predilection for the eye rather than for the respiratory tract [28]. For unknown reasons, one 57-year-old veterinarian died from a primary viral pneumonia followed by acute respiratory distress syndrome and related complications [14]. Though serologic investigations suggest that about 250 humans may have become exposed, it is unlikely that the virus transmitted extensively from person-to-person [13].

The HP H5N1 outbreak that started in poultry in several Asian countries in 2003 is the largest and most devastating in history. The virus is now enzootic in poultry in several countries in Asia and it has spread to more than 50 countries on three continents. Table III gives an overview of the countries that have reported human infections with $\mathrm{H} 5 \mathrm{~N} 1$ in chronological order. Most cases had a history of very close contact with infected poultry, usually within a week before the onset of clinical signs [10,19]. Inhalation of infectious droplets and self-inoculation of the conjunctival or upper respiratory tract mucosa are probably the most common routes of infection. The first and most prominent clinical signs are a high fever $\left(\geq 38{ }^{\circ} \mathrm{C}\right)$ and influenza-like symptoms, but diarrhoea and gastro-intestinal signs are not uncommon. Symptoms of involvement of the lower respiratory tract - respiratory distress, difficulty in breathing and a crackling sound when inhaling - are typical. The pathogenesis of H5N1 in humans is not yet fully understood, but 
Table III. Avian influenza viruses isolated from humans since 1996.

\begin{tabular}{lccccc}
\hline \multirow{2}{*}{ Year } & Subtype-pathotype & Location & \multicolumn{2}{c}{ Number } & \multirow{2}{*}{ Symptoms } \\
\cline { 3 - 4 } & & Infected & Dead & \\
\hline 1996 & H7N7-LPAI & USA & 1 & 0 & Conjunctivitis \\
1997 & H5N1-HPAI & Hong Kong & 18 & 6 & Influenza-like \\
$1998-1999$ & H9N2-LPAI & Hong Kong/China & 2 & 0 & Influenza-like \\
2003 & H5N1- ? & Hong Kong & 2 & 1 & Influenza-like \\
2003 & H7N7-HPAI & The Netherlands & 83 & 1 & Conjunctivitis \\
2004 & H7N3-HPAI & Canada (BC) & 2 & 0 & Conjunctivitis \\
$2004-. .{ }^{a}$ & H5N1-HPAI & Vietnam & 93 & 42 & Influenza-like \\
& & Thailand & 25 & 17 & \\
& & Indonesia & 74 & 56 & \\
& & Cambodia & 6 & 6 & \\
& & China & 21 & 14 & \\
& & Turkey & 12 & 4 & \\
& Iraq & 3 & 2 & \\
& & Azerbaijan & 8 & 5 & \\
& Egypt & 15 & 7 & \\
& & Djibouti & 1 & 0 & \\
& & & &
\end{tabular}

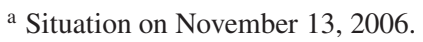

the lungs appear to be the major site of virus replication and viral antigen has been demonstrated in type 2 pneumocytes [52]. Almost all patients develop a primary viral pneumonia with diffuse alveolar damage, interstitial pneumonia, focal haemorrhages and bronchiolitis. There are indications that a prolonged overproduction of (pro-) inflammatory cytokines, such as TNF- $\alpha$, IL-6, IL-8 and IFN- $\gamma$, and chemokines lead to the acute respiratory distress syndrome and multi-organ failure that are seen in so many patients $[5,41,51]$. Reactive haemophagocytic syndrome - the proliferation of benign haemophagocytic histiocytes in haemopoietic and other organs including the lungs - is believed to be cytokine-driven and is one of the most prominent features in patients who died from H5N1. Recent virological and immunological investigations in $\mathrm{H} 5 \mathrm{~N} 1$ patients further support that the fatal outcome is associated with high virus replication in the respiratory tract and the resulting hypercytokinemia [11].

In several H5N1 patients, infectious virus or viral RNA have also been recovered from serum or plasma, cerebrospinal fluid or gastrointestinal samples [6,9,11,52]. Non-respiratory signs and diarrhoea in particular have also been reported in some patients. It is thus possible that $\mathrm{H} 5 \mathrm{~N} 1$ has a broader tissue tropism in humans than the common human influenza A virus subtypes, but proof is still lacking. It is often overlooked that $\mathrm{H} 1 \mathrm{~N} 1$ and $\mathrm{H} 3 \mathrm{~N} 2$ influenza viruses have also been isolated from extra-respiratory sites in some fatal cases of human influenza pneumonia. Most important, it remains unclear whether the detection of $\mathrm{H} 5 \mathrm{~N} 1$ or other influenza viruses outside the respiratory tract reflects genuine infection of other tissues. Viral antigen-positive 
cells have so far only been demonstrated in the lungs of $\mathrm{H} 5 \mathrm{~N} 1$ patients, and not in the intestinal tract for example, though we must take into account that relatively few extra-respiratory samples have been investigated. There is circumstantial evidence that some people in Asia have become infected through slaughtering and preparation of infected poultry and/or through consumption of contaminated (uncooked) poultry products. However, this does not mean that the gastrointestinal tract has served as a portal of virus entry in these cases and the infection could also have been initiated in susceptible cells in the oropharyngeal region or in the respiratory tract. Furthermore, gastrointestinal manifestations can also occur during normal seasonal influenza, especially in children [57].

At any rate, it must be stressed that H5N1 remains mainly a problem of birds and does not easily cross from birds to infect humans. Despite the infection of tens of millions of poultry over large geographical areas since mid-2003, only about 200 human cases have been laboratory confirmed. For unknown reasons, most of these cases have occurred in households with infected backyard poultry and very few cases have occurred in presumed high-risk groups, such as commercial poultry workers, cullers and veterinarians. The H5N1 virus so far fails to spread efficiently from human-to-human and eliminating the source of infection, i.e. infected birds, remains the most effective control measure. Recent in vitro work with respiratory tissues of humans has shown that $\mathrm{H} 5 \mathrm{~N} 1$ attaches preferably to epithelial cells in the lower respiratory tract, namely type 2 pneumocytes and epithelial cells in terminal bronchioles whereas attachment becomes progressively more rare towards the trachea $[45,55]$. This was in line with the observation that the receptor for AI viruses occurs only in and around the alveoli of the human lung but not in the nasal epithe- lium, trachea or bronchi, where the receptor for human influenza viruses predominates [45]. If the H5N1 virus really has difficulty in replicating in the upper region of the respiratory tract of humans, this may help explain why it spreads inefficiently to and between humans. It is also feared that mutations in the receptor-binding site of the viral HA would enable the virus to bind to receptors in the upper respiratory tract and that this could increase the risk of an $\mathrm{H} 5 \mathrm{~N} 1$ pandemic. However, it remains uncertain to what extent the in vitro data reflect the in vivo situation and comparative, quantitative analyses of the replication of both human and avian influenza viruses in nasal tissues of humans are also lacking.

\subsection{Swine as an intermediate host for the transmission of avian influenza viruses to humans?}

For a long time, it was thought that transmission of AI viruses to humans does not occur directly but via the pig as an intermediate host. However, several "old" theories obviously need to be revised and the recent HPAI outbreaks have also changed our understanding of the role of pigs.

Pigs are clearly susceptible to infection with both LP and HPAI viruses. LPAI viruses have been occasionally isolated from pigs in the field as shown in Table IV [17, 23, 24, 26, 40, 43]. Though most of these viruses have an $\mathrm{H} 1$ or $\mathrm{H} 3 \mathrm{HA}$, HA subtypes that are usually restricted to birds can also cross the species barrier to pigs. Serological investigations in Asia, for example, have shown evidence for infections of pigs with avian $\mathrm{H} 4, \mathrm{H} 5$ and $\mathrm{H} 9$ viruses [36]. Importantly, however, only the H1N1 virus that crossed from wild birds to swine in Europe in 1979 has become established in pigs, whereas the other viruses have disappeared. In an experimental study by Kida et al. [27], pigs 
Table IV. LPAI viruses that have been isolated from pigs since 1979.

\begin{tabular}{lllll}
\hline Year & Location & Subtype & Source of infection & $\begin{array}{l}\text { Extent } \\
\text { of transmission in } \\
\text { swine population }\end{array}$ \\
\hline 1979 & Western Europe & H1N1 & Wild ducks & Enzootic \\
1988 & Taiwan, South China & H3N2 & Wild ducks & No data \\
$1993-1994$ & South China & H1N1 & Wild ducks & Low prevalence \\
$1998-2000$ & South China & H9N2 & Wild ducks & Low prevalence \\
1999 & Canada & H4N6 & Wild ducks & Single isolation \\
2001 & Canada & H3N3 & Wild ducks & Single isolation \\
2001,2002 & Canada & H1N1 & Wild ducks & Single isolation \\
\hline
\end{tabular}

were inoculated intranasally with 38 LPAI viruses, mainly of duck origin, and 29 of them were excreted in nasal swabs and induced a serological response. The pathogenesis of such viruses, however, and their potential for transmission between pigs have never been examined. In the author's lab we have been able to confirm that most LPAI viruses are able to infect pigs after experimental intranasal inoculation of a high virus dose, but we also have strong indications that AI viruses replicate much less efficiently than the typical SIV. It is not so surprising, therefore, that the circulation of entirely AI viruses in pigs in nature is a relatively rare event. Still, there is circumstantial evidence that the genes of avian viruses may persist after reassortment with one or more influenza viruses endemic in pigs. As an example, H3N2 and H1N2 influenza viruses carrying mixtures of avian, swine and human influenza virus genes have become enzootic in Europe and North America. This probably means that genetic reassortment or mutations are needed for successful transmission of AI viruses between pigs.

HPAI viruses can and do infect pigs under natural and experimental conditions. But as for LPAI viruses, it is doubtful whether HPAI viruses replicate efficiently in pigs and whether they are readily transmitted among pigs. During the HP H7N7 outbreak in The Netherlands in 2003,
H7N7 antibodies were temporarily found on some mixed farms with swine and infected poultry, but not on mixed farms with non-infected poultry or on farms with swine only [32]. After experimental intranasal inoculation with a high dose of the H7N7 virus, pigs shed virus in nasal swabs for one or a few days and showed seroconversion, but there was no disease or virus transmission to contact animals. Antibodies to the Asian $\mathrm{H} 5 \mathrm{~N} 1$ virus were found in only $0.25 \%$ of 3175 pigs tested in Vietnam in 2004, where H5N1 has hit the hardest [7]. There are also unpublished reports of occasional infection with $\mathrm{H} 5 \mathrm{~N} 1$ in pigs in China in 2001 and 2003, and more recently in Indonesia. In three different experimental studies, pigs have been inoculated intranasally with a high dose $\left(\geq 10^{6}\right.$ EID50) of Asian HP H5N1 influenza viruses $[7,21,46]$. Six of the total 8 H5N1 isolates tested were shown to replicate in pigs. Despite the extreme virulence of the viruses for poultry, the pigs showed only mild or no clinical signs. Virus titres in nasal swabs were moderate, and there was no virus transmission between experimentally inoculated and in-contact pigs. In one study, H5N1 virus was isolated from the respiratory tract (tonsils, trachea and lungs) of pigs but not from the intestines, blood, spleen or kidney [7]. Unfortunately, all these studies were performed on a very limited number of pigs and detailed studies 
of the cell and organ tropism of H5N1 in pigs are still lacking.

Pigs are also considered as prime candidates for the generation of reassortants between human and avian influenza viruses. Such reassortants may replicate much better in humans than wholly avian viruses, which are generally unable to spread in the human population. The pandemic human influenza viruses of 1957 and 1968 were human-avian reassortants (reviewed in [57]) and one classical theory is that reassortment occurred in the pig, which served as an intermediate host to transfer the virus to humans. One finding in particular has contributed to the hypothesis of the pig as a "mixing vessel", namely the observation that the trachea of pigs contains receptors for both avian and human influenza viruses [22]. It must be recalled here that the binding of a virus to receptor molecules on the surface of the target cell is the very first step in the viral replication cycle. The distal tip of the HA of the influenza virus is responsible for binding the virus receptor, which is "sialic" or "neuraminic" acid, a sugar group commonly found on a variety of glycosylated molecules. Although all influenza viruses recognise sialic acid, the type of sialic acid linkage with galactose and the receptor specificity of the viral HA differ between host species and this is thought to be a major determinant of the species specificity of influenza A viruses. In addition, small mutations in the receptor-binding site of the HA may change the host range of influenza viruses. In the epithelial cells of duck intestine, the preferential virus replication site in ducks, sialic acid is joined to the sugar chain through an $\alpha 2,3$ linkage, and viruses isolated from wild birds possess HA with high affinity for this type of sugar [22]. In the human trachea, terminal sialic acid is linked through an $\alpha 2,6$ bond [2] and viruses circulating in humans favour binding to $\alpha 2,6$ [8]. However, it was recently discovered that not only pigs but also hu- mans have receptors for both human and avian influenza viruses, which predominate in the upper and lower respiratory tracts respectively [45]. This is in line with the current knowledge that AI viruses can transmit to humans without the pig as an intermediary and that genetic reassortment can also occur in humans. Because of our limited knowledge of the extent of replication of the Asian $\mathrm{H} 5 \mathrm{~N} 1$ virus in pigs, it is difficult to estimate whether there is a real chance for reassortment of this virus in a pig.

\section{GENERAL CONSIDERATIONS ON THE SPECIES BARRIER AND CONCLUSIONS}

There are many factors that limit the transmission of influenza viruses from one species to another and they are incompletely understood. An excellent summary of our current knowledge of the "host species barriers to influenza virus infections" has recently been published [29]. A first possible barrier is a lack of suitable receptors on the host cell, so that the HA of a virus from another species cannot attach. AI viruses prefer sialic acid receptors with an $\alpha 2,3$ linkage to galactose, while human viruses have a preference for sialic acids with an $\alpha 2,6$ linkage. The paucity of AI virus receptors in the nose and trachea of humans may hamper transmission of avian viruses to and between humans. However, this theory is still a mere hypothesis and it certainly needs further proof. Even if an influenza virus succeeds to enter the cell of a new host, it must successfully coopt host cell processes to replicate there. The polymerases of the virus, which are responsible for the replication and transcription of viral RNA, play a key role at this stage. As an example, many AI viruses can infect mouse cells but fail to replicate in them and this has been associated with specific amino acids in the polymerase 
B2 proteins (PB1, PB2, PA) [15, 44]. Finally, the influenza virus must escape from the cell it has infected. During this step, the viral HA tends to re-bind to receptors on the cell surface and the NA helps to break this binding. Like the HA, the NA also has a preference for one of both types of sialic acid linkages and thus for humans or birds. Another important concept is that cross-species transmission per se is clearly insufficient to generate a human influenza pandemic and that the crosstransmitted virus must further adapt to the new human host in order to replicate efficiently and to become established in the human population. It is reassuring that a large number of viral mutations, or genetic reassortments, are obviously needed for this adaptation and that most of such genetic changes will be deleterious for the virus. The exact nature of these changes remains unknown and the genetic basis of influenza virus transmissibility appears to be highly complex. Recent research has shown that reassortment in itself is insufficient for the generation of a pandemic influenza virus and that additional genetic changes are likely required [33]. In this interesting study, reassortants between a human H3N2 influenza virus and the 1997 $\mathrm{H} 5 \mathrm{~N} 1$ virus were used in experimental infections of ferrets, which are considered the best small animal model of human influenza. The hybrids with H3N2's surface proteins and $\mathrm{H} 5 \mathrm{~N} 1$ internal proteins replicated well but did not transmit as easily between ferrets as the original H3N2 virus. The most feared combinations - reassortants with H5N1's HA and NA and internal human virus proteins - not only did not replicate as well as $\mathrm{H} 5 \mathrm{~N} 1$ but also failed to spread between ferrets.

Other factors that will influence influenza virus transmission between species are non-specific immune mechanisms, the routes of virus dissemination/excretion by the "donor" host, the extent of contact between donor and "recipient" host and the influenza immune status of the new host. It cannot be excluded that people with a solid immunity to the N1 neuraminidase of a human H1N1 influenza virus may be partially protected against H5N1. Moreover, some experimental studies have shown shortterm immunity between different influenza subtypes [35].

Many basic questions about the pathogenesis of influenza in natural and unnatural hosts also remain unanswered. Do the usual human influenza virus subtypes replicate better in the upper respiratory tract of humans, as claimed by the authors of two recent in vitro studies [45,55], or in the lower respiratory tract, as mentioned in so many textbooks $[3,16,57]$ ? And does the respiratory tropism of $\mathrm{H} 5 \mathrm{~N} 1$ in humans really differ from that of the human influenza viruses? Can influenza viruses infect extrarespiratory tissues in humans and does this occur more frequently with H5N1? As for mammalian species other than humans, detailed studies on the pathogenesis of $\mathrm{H} 5 \mathrm{~N} 1$ have only been performed in cats. Because of all these gaps in our knowledge, we cannot say which animal species could be a reliable model for human $\mathrm{H} 5 \mathrm{~N} 1$ infection.

The possible role of pigs in the generation of new pandemic influenza strains appears to be more limited than previously thought. The old theory is that pigs are more susceptible to AI viruses than humans and that they serve as intermediates for the transmission of AI viruses to humans. Still, this hypothesis has never been proven and it is questioned by some recent observations with $\mathrm{HP}$ H7N7 and H5N1 AI viruses. The current viewpoint is that a strong barrier exists to infection of pigs with influenza viruses from other species, and that major genetic changes are required for consistent pig-to-pig transmission of such viruses. We have only started to gain some insights into the nature of these genetic changes. We also need detailed studies on the pathogenesis of influenza viruses from birds and other 
species in pigs. Only this way, speculations on the role of pigs will turn into knowledge.

\section{REFERENCES}

[1] Alexander D.J., A review of avian influenza in different bird species, Vet. Microbiol. (2000) 74:3-13.

[2] Baum L.G., Paulson J.C., Sialyloligosaccharides of the respiratory epithelium in the selection of human influenza virus receptor specificity, Acta Histochem. (1990) Suppl. 40:35-38.

[3] Betts R.F., Douglas R.G., Influenza virus, in: Mandell G.L., Douglas R.G., Benett J.E. (Eds.), Principles and practice of infectious diseases, Churchill Livingstone, New York, USA, 1990, pp. 1306-1325.

[4] Capua I., Alexander D.J., Human health implications of avian influenza viruses and paramyxoviruses, Eur. J. Clin. Microbiol. Infect. Dis. (2004) 23:1-6.

[5] Cheung C.Y., Poon L.L., Lau A.S., Luk W., Lau Y.L., Shortridge K.F., Gordon S., Guan Y., Peiris J.S., Induction of proinflammatory cytokines in human macrophages by influenza A (H5N1) viruses: a mechanism for the unusual severity of human disease? Lancet (2002) 360:1831-1837.

[6] Chutinimitkul S., Bhattarakosol P., Srisuratanon S., Eiamudomkan A., Kongsomboon K., Damrongwatanapokin S., Chaisingh A., Suwannakarn K., Chieochansin T., Theamboonlers A., Poovorawan Y., H5N1 influenza A virus and infected human plasma, Emerg. Infect. Dis. (2006) 12:1041-1043.

[7] Choi Y.K., Nguyen T.D., Ozaki H., Webby R.J., Puthavathana P., Buranathal C., Chaisingh A., Auewarakul P., Hanh N.T., Ma S.K., Hui P.Y., Guan Y., Peiris J.S., Webster R.G., Studies of H5N1 influenza virus infection of pigs by using viruses isolated in Vietnam and Thailand in 2004, J. Virol. (2005) 79:10821-10825.

[8] Connor R.J., Kawaoka Y., Webster R.G., Paulson J.C., Receptor specificity in human, avian, and equine $\mathrm{H} 2$ and $\mathrm{H} 3$ influenza virus isolates, Virology (1994) 205:17-23.

[9] De Jong M.D., Bach V.C., Phan T.Q., Vo M.H., Tran T.T., Nguyen B.H., Beld M., Le T.P., Truong H.K., Nguyen V.V., Tran T.H., Do H.Q., Farrar J., Fatal avian influenza A (H5N1) in a child presenting with diarrhoea followed by coma, N. Engl. J. Med. (2005) 352:686-691.
[10] De Jong M.D., Hien T.T., Avian influenza A (H5N1), J. Clin. Virol. (2006) 35:2-13.

[11] De Jong M.D., Simmons C.P., Thanh T.T., Hien V.M., Smith G.J.D., Chau T.N.B., Hoang D.M., Chau N.V.V., Khanh T.H., Dong V.C., Qui P.T., Cam B.V., Ha D.Q., Guan Y., Peiris J.S.M., Chinh N.T., Hien T.T., Farrar J., Fatal outcome of human influenza A (H5N1) is associated with high viral load and hypercytokinemia, Nat. Med. (2006) 12:1203-1207.

[12] Ellis J.S., Alvarez-Aguero A., Gregory V., Lin Y.P., Hay A., Zambon M.C., Influenza A H1N2 viruses, United Kingdom, 2001-2002 influenza season, Emerg. Infect. Dis. (2003) 9:304-310.

[13] Enserink M., Bird flu infected 1000, Dutch researchers say, Science (2004) 306:590.

[14] Fouchier R.A., Schneeberger P.M., Rozendaal F.W., Broekman J.M., Kemink S.A., Munster V., Kuiken T., Rimmelzwaan G.F., Schutten M., Van Doornum G.J., Koch G., Bosman A., Koopmans M., Osterhaus A.D., Avian influenza A virus (H7N7) associated with human conjunctivitis and a fatal case of acute respiratory distress syndrome, Proc. Natl. Acad. Sci. USA (2004) 101:1356-1361.

[15] Gabriel G., Dauber B., Wolff T., Planz O., Klenk H.-D., Stech J., The viral polymerase mediates adaptation of an avian influenza virus to a mammalian host, Proc. Natl. Acad. Sci. USA (2005) 102:18590-18595.

[16] Glezen W.P., Couch R.B., Influenza viruses, in: Fraser R.G., Paré J.A. (Eds.), Diagnosis of diseases of the chest, W.B. Saunders Company, Philadelphia, USA, 1990, pp. 419-449.

[17] Guan Y., Shortridge K.F., Krauss S., Li P.H., Kawaoka Y., Webster R.G., Emergence of avian $\mathrm{H} 1 \mathrm{~N} 1$ influenza viruses in pigs in China, J. Virol. (1996) 70:8041-8046.

[18] Hay A.J., Gregory V., Douglas A.R., Lin Y.P., The evolution of human influenza viruses, Philos. Trans. R. Soc. Lond. B Biol. Sci. (2001) 356:1861-1870.

[19] Hayden F., Croisier A., Transmission of avian influenza viruses to and between humans, J. Infect. Dis. (2005) 192:1311-1314.

[20] Hayden F.G., Fritz R., Lobo M.C., Alvord W., Strober W., Straus S.E., Local and systemic cytokine responses during experimental human influenza A virus infection. Relation to symptom formation and host defense, J. Clin. Invest. (1998) 101:643-649. 
[21] Isoda N., Sakoda Y., Kishida N., Bai G.R., Matsuda K., Umemura T., Kida H., Pathogenicity of a highly pathogenic avian influenza virus, A/chicken/Yamaguchi/7/04 (H5N1) in different species of birds and mammals, Arch. Virol. (2006) 151:12671279.

[22] Ito T., Couceiro J.N., Kelm S., Baum L.G., Krauss S., Castrucci M.R., Donatelli I., Kida H., Paulson J.C., Webster R.G., Kawaoka Y., Molecular basis for the generation in pigs of influenza A viruses with pandemic potential, J. Virol. (1998) 72:7367-7373.

[23] Karasin A.I., Olsen C.W., Brown I.H., Carman S., Stalker M., Josephson G., H4N6 influenza virus isolated from pigs in Ontario, Can. Vet. J. (2000) 41:938-939.

[24] Karasin A.I., West K., Carman S., Olsen C.W., Characterization of avian H3N3 and H1N1 influenza A viruses isolated from pigs in Canada, J. Clin. Microbiol. (2004) 42:4349-4354.

[25] Kawaoka Y., Bordwell E., Webster R.G., Intestinal replication of influenza A viruses in two mammalian species, Arch. Virol. (1987) 93:303-308.

[26] Kida H., Shortridge K.F., Webster R.G., Origin of the hemagglutinin gene of $\mathrm{H} 3 \mathrm{~N} 2$ influenza viruses from pigs in China, Virology (1988) 162:160-166.

[27] Kida H., Ito T., Yasuda J., Shimizu Y., Itakura C., Shortridge K.F., Kawaoka Y., Webster R.G., Potential for transmission of avian influenza viruses to pigs, J. Gen. Virol. (1994) 75:2183-2188.

[28] Koopmans M., Wilbrink B., Conyn M., Natrop G., van der Nat H., Vennema H., Meijer A., van Steenbergen J., Fouchier R., Osterhaus A., Bosman A., Transmission of H7N7 avian influenza A virus to human beings during a large outbreak in commercial poultry farms in the Netherlands, Lancet (2004) 363:587-593.

[29] Kuiken T., Holmes E.C., McCauley J., Rimmelzwaan G.F., Williams C.S., Grenfell B.T., Host species barriers to influenza virus infections, Science (2006) 312:394-397.

[30] Kurtz J., Manvell R.J., Banks J., Avian influenza virus isolated from a woman with conjunctivitis (letter), Lancet (1996) 348:901-902.

[31] Li K.S., Guan Y., Wang J., Smith G.J., $\mathrm{Xu}$ K.M., Duan L., Rahardjo A.P., Puthavathana P., Buranathai C., Nguyen T.D., Estoepangestie A.T., Chaisingh A., Auewarakul P., Long H.T., Hanh N.T.,
Webby R.J., Poon L.L., Chen H., Shortridge K.F., Yuen K.Y., Webster R.G., Peiris J.S., Genesis of a highly pathogenic and potentially pandemic $\mathrm{H} 5 \mathrm{~N} 1$ influenza virus in eastern Asia, Nature (2004) 430:209-213.

[32] Loeffen W., de Boer E., Koch G., Transmission of a highly pathogenic avian influenza virus to swine in the Netherlands, Proceedings of the in-between congress of the International Society for Animal Hygiene, St. Malo, France, 2004, pp. 329-330.

[33] Maines T.R., Chen L.M., Matsuoka Y., Chen H., Rowe T., Ortin J., Falcon A., Nguyen T.H., Maile Q., Sedyaningsih E.R., Harun S., Tumpey T.M., Donis R.O., Cox N.J., Subbaro K., Katz J.M., Lack of transmission of H5N1 avian-human reassortant influenza viruses in a ferret model, Proc. Natl. Acad. Sci. USA (2006) 103:12121-12126.

[34] Myers K.P., Olsen C.W., Setterquist S.F., Capuano A.W., Donham K.J., Thacker E.L., Merchant J.A., Gray G.C., Are swine workers in the United States at increased risk of infection with zoonotic influenza virus? Clin. Infect. Dis. (2006) 42:14-20.

[35] Nguyen H.H., Moldoveanu Z., Novak M.W., van Ginkel F.W., Ban E., Kiyono H., McGhee J.R., Mestecky J., Heterosubtypic immunity to lethal influenza A virus infection is associated with virus-specific CD8+ cytotoxic lymphocyte responses induced in mucosa-associated tissues, Virology (1999) 254:50-60.

[36] Ninomiya A., Takada A., Okazaki K., Shortridge K.F., Kida H., Seroepidemiological evidence of avian $\mathrm{H} 4, \mathrm{H} 5$, and $\mathrm{H} 9$ influenza A virus transmission to pigs in southeastern China, Vet. Microbiol. (2002) 88:107-114.

[37] Olsen C.W., Brammer L., Easerday B.C., Arden N., Belay E., Baker I., Cox N., Serologic evidence of $\mathrm{H} 1$ swine influenza virus infection in swine farm residents and employees, Emerg. Infect. Dis. (2002) 8:814-819.

[38] Olsen C.W., Brown I.H., Easterday B.C., Van Reeth K., Swine influenza, in: Straw B.E., Zimmerman J.J., d'Allaire S., Taylor D.J. (Eds.), Disease of swine, Blackwell Publishing, Oxford, UK, 2006, pp. 469-482.

[39] Olsen B., Munster V.J., Wallensten A., Waldenström J., Osterhaus A.D.M.E., Fouchier R.A.M., Global patterns of influenza A virus in wild birds, Science (2006) 312:384-388. 
[40] Peiris J.S., Guan Y., Markwell D., Ghose P., Webster R.G., Shortridge K.F., Cocirculation of avian H9N2 and contemporary "human" $\mathrm{H} 3 \mathrm{~N} 2$ influenza A viruses in pigs in southeastern China: potential for genetic reassortment? J. Virol. (2001) 75:9679-9686.

[41] Peiris J.S.M., Yu W.C., Leung C.W., Cheung C.Y., Ng W.F., Nicholls J.M., Ng T.K., Chan K.H., Lai S.T., Lim W.L., Yuen K.Y., Guan Y., Re-emergence of fatal human influenza A subtype H5N1 disease, Lancet (2004) 363:617-619.

[42] Peiris M., Yuen K.Y., Leung C.W., Chan K.H., Ip P.L., Lai R.W., Orr W.K., Shortridge K.F., Human infection with influenza H9N2, Lancet (1999) 354:916-917.

[43] Pensaert M., Ottis K., Vandeputte J., Kaplan M.M., Bachmann P.A., Evidence for the natural transmission of influenza A virus from wild ducks to swine and its potential importance for man, Bull. World Health Organ. (1981) 59:75-78

[44] Salomon R., Franks J., Govorkova E.A., Ilyushina N.A., Yen H.-L., Hulse-Post D.J., Humberd J., Trichet M., Rehg J.E., Webby R.J., Webster R.G., Hoffmann E., The polymerase complex genes contribute to the high virulence of the human $\mathrm{H} 5 \mathrm{~N} 1$ influenza virus isolate A/Vietnam/1203/04, J. Exp. Med. (2006) 203:689-697.

[45] Shinya K., Ebina M., Yamada S., Ono M., Kasai N., Kawaoka Y., Influenza virus receptors in the human airway, Nature (2006) 440:435-436.

[46] Shortridge K.F., Zhou N.N., Guan Y., Gao P., Ito T., Kawaoka Y., Kodihalli S., Krauss S., Markwell D., Murti K.G., Norwood M., Senne D., Sims L., Takada A., Webster R.G., Characterization of avian H5N1 influenza viruses from poultry in Hong Kong, Virology (1998) 252:331-342.

[47] Shortridge K.F., Gao P., Guan Y., Ito T., Kawaoka Y., Markwell D., Takada A., Webster R.G., Interspecies transmission of influenza viruses: H5N1 virus and a Hong Kong SAR perspective, Vet. Microbiol. (2000) 74:141-147.

[48] Sims L.D., Domenech J., Benigno C., Kahn S., Kamata A., Lubroth J., Martin V., Roeder P., Origin and evolution of highly pathogenic H5N1 avian influenza in Asia, Vet. Rec. (2005) 157:159-164.

[49] Sturm-Ramirez K.M., Hulse-Post D.J., Govorkova E.A., Humberd J., Seiler P.,
Puthavathana P., Buranathai C., Nguyen T.D., Chaisingh A., Long H.T., Naipospos T.S.P., Chen H., Ellis T.M., Guan Y., Peiris J.S.M., Webster R.G., Are ducks contributing to the endemicity of highly pathogenic H5N1 influenza in Asia? J. Virol. (2005) 79:11269-11279.

[50] Swayne D.E., Halvorson D.A., Influenza, in: Saif Y.M., Barnes H.J., Glisson J.R., Fadly A.M., McDougald L.R., Swayne D.E. (Eds.), Disease of poultry, Iowa State Press, Ames, Iowa, USA, 2003, pp. 135-160.

[51] To K., Chan P.K.S., Chan K., Lee W., Lam W., Wong K., Tang N.L.S., Tsang D.N.C., Sung R.Y.T., Buckley T.A., Tam J.S., Cheng A.F., Pathology of fatal human infection associated with avian influenza A H5N1 virus, J. Med. Virol. (2001) 63:242-246.

[52] Uiprasertkul M., Puthavathana P. Sangsiriwut K., Pooruk P., Srisook K. Peiris M., Nicholls J.M., Chokephaibulkit K., Vanprapar N., Auewarakul P., Influenza A H5N1 replication sites in humans, Emerg. Infect. Dis. (2005) 11:1036-1041.

[53] Van Reeth K., Nauwynck H., Pensaert M., Bronchoalveolar interferon-alpha, tumor necrosis factor-alpha, interleukin-1, and inflammation during acute influenza in pigs: a possible model for humans? J. Infect. Dis. (1998) 177:1076-1079.

[54] Van Reeth K., Van Gucht S., Pensaert M., Correlations between lung proinflammatory cytokine levels, virus replication, and disease after swine influenza virus challenge of vaccination-immune pigs, Viral Immunol. (2002) 15:583-594

[55] Van Riel D., Munster V.J., de Wit E., Rimmelzwaan G.F., Fouchier R.A.M., Osterhaus A.D., Kuiken T., H5N1 virus attachment to lower respiratory tract, Science (2006) 312:399.

[56] Webster R.G., Yakhno M., Hinshaw V.S. Bean W.J., Murti K.G., Intestinal Influenza: replication and characterization of influenza viruses in ducks, Virology (1978) 84:268278.

[57] Wright P.F., Webster R.G., Orthomyxoviruses, in: Knipe D.M., Howley P.M. Griffin D.E., Lamb R.A., Martin M.A., Roizman B., Straus S.E. (Eds.), Field's virology, Lippincott-Raven Publishers, Philadelphia, USA, 2001, pp.1533-1579.

[58] Zambon M.C., The pathogenesis of influenza in humans, Rev. Med. Virol. (2005) 11:227241. 